\title{
ES Research Square

\section{Impacts of English Language Proficiency on Healthcare Access, use, and Outcomes among Immigrants: A Qualitative Study}

\section{Mamata Pandey ( $\sim$ Mamata.Pandey@saskhealthauthority.ca )}

Saskatchewan Health Authority

\section{Geoffrey Maina}

University of Saskatchewan

Jonathan Amoyaw

Dalhousie University

Yiyan Li

University of Saskatchewan

Rejina Kamrul

University of Saskatchewan

Clara Rocha Michaels

University of Saskatchewan

\section{Razawa Maroof}

University of Saskatchewan

\section{Research Article}

Keywords: language barrier, immigrants, healthcare access, healthcare utilisation, health outcomes

Posted Date: March 16th, 2021

DOl: https://doi.org/10.21203/rs.3.rs-291909/v1

License: (9) (i) This work is licensed under a Creative Commons Attribution 4.0 International License. Read Full License

Version of Record: A version of this preprint was published at BMC Health Services Research on July 26th, 2021. See the published version at https://doi.org/10.1186/s12913-021-06750-4. 


\section{Abstract}

Background: Immigrants from culturally, ethnically, and linguistically diverse countries face many challenges during the resettlement phase, which influences their access to healthcare services and health outcomes. Healthy immigrant effect or the health advantage that immigrants arrive with is observed to deteriorate with increased length of stay in the host country.

Methods: An exploratory qualitative design, following community based research approach was followed. The research team consisted of health researchers, clinicians, and community members. The objective was to explore the barriers to healthcare access among immigrants with limited English language proficiency. Three focus groups were carried out with 29 women and nine men attending English language classes at a settlement agency in a mid-sized city. Additionally, 17 individual interviews were carried out with healthcare providers caring for immigrants and refugees.

Results: Thematic analysis was carried out with transcribed focus groups and healthcare provider interview data. Both the healthcare providers and the immigrants indicated that limited language proficiency often delayed access to already available healthcare services and interfered with the development of a therapeutic relationship between the client and the healthcare provider. Language barriers also impeded effective communication between healthcare providers and clients, leading to suboptimal care and dissatisfaction with the care received. Language limitations interfered with treatment adherence and the use of preventative and screening services, further delaying access to timely care, causing poor chronic disease management, and ultimately resulting in poor health outcomes. Involving untrained interpreters, family members, or others from the ethnic community was problematic due to misinterpretation and confidentiality issues.

Conclusions: The study emphasises the need to provide language assistance during medical consultations to address language barriers among immigrants. The development of guidelines for recruitment, training, and effective engagement of language interpreters during medical consultation is recommended to ensure high quality, equitable and client-centered care.

\section{Background}

To address skilled labour shortages and compensate for aging populations, many countries, such as Australia, Germany, United States, and Canada, admit immigrants from ethnically, culturally, and linguistically diverse countries [1]. According to the 2016 Canadian Census, foreign-born individuals make up more than one-fifth $(21.9 \%)$ of the Canadian population, which is close to the highest level $(22.3 \%)$, recorded in the 1921 Census [2]. Most immigrants to Canada come from countries like the Philippines, India, China, Iran, and Pakistan where most citizens' first language is neither English nor French [3, 4]. Due to immigration requirements, most newcomers are healthier than the general population referred to as the "healthy immigrant effect". This effect tends to decline over time [5-7]. Thomson et al. (2011) observed 
that one out of four immigrants experiencing health decline also reported experiencing challenges accessing Canadian healthcare services.

As Canada's ethnic composition becomes more diverse, additional research is warranted to understand immigrants' settlement experiences and its impacts on their health outcomes [8]. Identifying postimmigration factors impacting health will help providers develop strategies to better support immigrants in maintaining the health advantage they arrive with, facilitate their integration into Canadian society as healthy and productive members, and maintain a good quality of life [9].

Our literature review indicated that systematic factors, such as geographic access, economic barriers, limited hours of operation, transportation, and the host country's healthcare delivered model, act as barriers to healthcare access and affect immigrants' and refugees' health outcomes [3, 10-. Additionally, person-specific factors, such as language barriers, difficulty navigating the healthcare system, lack of social support and cultural differences, further aggravate healthcare access challenges for immigrants and refugees $[3,9,11,13.14]$.

The ability to speak the official language of the host country proficiently, is an essential determinant of health $[7,14-16]$. The ability to speak, read, and write in the local language is necessary to communicate with healthcare providers and interact in other social settings $[17,18]$. Language is consistently identified as a barrier for immigrants and refugees seeking, accessing, and using mental health services $[5,15,19$, 20]. Marshall, Wong, Haggerty, and Levesque (2010) observed that Chinese- and Punjabi-speaking individuals with limited English language proficiency might delay accessing healthcare to find providers who spoke their language. In the absence of culture-specific words and due to stigma, individuals from some ethnic groups may describe mental health conditions through somatic symptoms [6, 21-23].

[Language-incongruent encounters within the healthcare system have increased the risk of misdiagnosis, medication errors and complications, and even death $[15,24]$. Studies indicate that language barriers have adversely affected health outcomes; healthcare access, utilization and cost; health-provider effectiveness; and patient satisfaction and safety [15, 24-32]. The impacts of local language proficiency on immigrants' health and well-being are relevant for any major immigrant-destination country, like Canada, the United Kingdom, the United States of America and others [15, 17, 24].

Collaboration between language-minority immigrant communities and healthcare providers is required to promote culturally sensitive programs that address language barriers in the Canadian healthcare system [33]. Given the unique history, culture, ethnic composition, and organization of healthcare services in Canada, scholars have highlighted the need for Canadian-based studies exploring how language barriers contribute to inefficiencies within the Canadian healthcare system [15, 34]. Therefore, this study explores how language influences various aspects of healthcare delivery and health outcomes from the perspective of immigrants and healthcare providers in a Canadian province that is witnessing a rapid influx of immigrants [2]. 


\section{Methods}

The study was set in a mid-size prairie city. An exploratory qualitative research approach guided by the principles of community-based research methods was adopted.

Clinicians on the research team experienced many barriers while caring for immigrants and refugees with language barriers and approached the community members for their perspective. The study idea was conceived after collective brainstorming with multi-sectoral stakeholders: representatives from a nongovernment settlement agency providing various settlement services to immigrants, family physicians caring for immigrants and refugees in the city, and health researchers. Each stakeholder represented a specific ethnic-minority group and arrived in Canada as a landed immigrant. Through personal experiences and professional interactions with other immigrants, the stakeholders knew about barriers experienced during healthcare access.

Thereafter, stakeholders developed a research partnership. They collectively decided to document these challenges and leverage the research results to advocate for improved healthcare services. The study aim was to explore the perspectives of immigrants and of healthcare providers. Community partners assisted the research team finalize the research question and determine methods of participants recruitment.

The study carried out in two parts, were approved by the provincial health authority's research ethics board (REB 14-122 and REB 15-69).

\section{Part 1}

\section{Participants.}

A purposeful sampling method was used and community partners assisted with participant recruitment by engaging those seeking services through a settlement agency The consent form and roles of research participants was shared with 43 individuals attending English language classes as the settlement agency.

Language assistance was provided by interpreters and the English language teachers facilitating the classes. Thirty-seven individuals ( 28 female and nine male) from 15 different countries signed consent forms. Three participants were travelling, two just began English language classes and one participant was not interested, were excluded. All participants had lived in Canada for less than six years and are thereafter referred to as "clients." Please refer to demographic information collected after clients signed the consent form in Table 1. 
Table 1

Sociodemographic and current health information recorded from participants, by gender.

\begin{tabular}{|c|c|c|}
\hline & Female & Male \\
\hline$n(\%)$ & $28(75.7 \%)$ & $\begin{array}{l}9 \\
(24.3 \%)\end{array}$ \\
\hline What is your Age $(\mathrm{M}, \mathrm{SD})$ & $37.6(7.9)$ & $41.1(7.1)$ \\
\hline \multicolumn{3}{|l|}{ What is your Marital Status n (\%) } \\
\hline Married or common law & $\begin{array}{l}25 \\
(89.3 \%)\end{array}$ & $8(88.9 \%)$ \\
\hline Divorced & $1(3.6 \%)$ & $\begin{array}{l}1 \\
(11.1 \%)\end{array}$ \\
\hline Missing & $2(7.1 \%)$ & $\mathrm{N} / \mathrm{A}$ \\
\hline \multicolumn{3}{|c|}{ What level of Education you completed n (\%) } \\
\hline Elementary Schooling (grade 10) & $1(3.6 \%)$ & $\begin{array}{l}1 \\
(11.1 \%)\end{array}$ \\
\hline High school & $5(17.9 \%)$ & $\begin{array}{l}5 \\
(55.6 \%)\end{array}$ \\
\hline Trades and or vocation & $1(3.6 \%)$ & $\begin{array}{l}1 \\
(11.1 \%)\end{array}$ \\
\hline Undergraduate & $\begin{array}{l}18 \\
(64.2 \%)\end{array}$ & $\begin{array}{l}2 \\
(22.2 \%)\end{array}$ \\
\hline University & $1(3.6 \%)$ & $\mathrm{N} / \mathrm{A}$ \\
\hline Missing & $3(10.7 \%)$ & $\mathrm{N} / \mathrm{A}$ \\
\hline \multicolumn{3}{|l|}{ How many child do you have $\mathrm{n}(\%)$} \\
\hline 0 & $5(18 \%)$ & $\mathrm{N} / \mathrm{A}$ \\
\hline $1-3$ & $20(71 \%)$ & $\begin{array}{l}8 \\
(88.9 \%)\end{array}$ \\
\hline$>3$ & $2(7.1 \%)$ & $\begin{array}{l}1 \\
(11.1 \%)\end{array}$ \\
\hline missing & $1(3.6 \%)$ & $\mathrm{N} / \mathrm{A}$ \\
\hline \multicolumn{3}{|c|}{ How many other individuals live with you in the same house $n(\%)$} \\
\hline $1-3$ & $\begin{array}{l}17 \\
(60.7 \%)\end{array}$ & $\begin{array}{l}3 \\
(33.3 \%)\end{array}$ \\
\hline $4-6$ & $\begin{array}{l}10 \\
(35.7 \%)\end{array}$ & $\begin{array}{l}3 \\
(33.3 \%)\end{array}$ \\
\hline
\end{tabular}




\begin{tabular}{|c|c|c|}
\hline & Female & Male \\
\hline$>6$ & $\mathrm{~N} / \mathrm{A}$ & $\begin{array}{l}1 \\
(11.1 \%)\end{array}$ \\
\hline Alone & N/A & $\begin{array}{l}1 \\
(11.1 \%)\end{array}$ \\
\hline Missing & $1(3.6 \%)$ & $\begin{array}{l}1 \\
(11.1 \%)\end{array}$ \\
\hline \multicolumn{3}{|l|}{ What is the total family income in a year? $\mathrm{n}(\%)$} \\
\hline $0-\$ 30,000$ & $9(32.1 \%)$ & $\begin{array}{l}1 \\
(11.1 \%)\end{array}$ \\
\hline$\$ 30,000-\$ 50,000$ & $6(21.4 \%)$ & $2(22.2 \%)$ \\
\hline$\$ 50,000-\$ 100,000$ & $4(14.3 \%)$ & $33.3 \%$ \\
\hline Missing & $9(32.1 \%)$ & $\begin{array}{l}3 \\
(33.3 \%)\end{array}$ \\
\hline How long have you stayed in Canada?: Mean (SD) years & $2.8(1.9)$ & $3.4(.15)$ \\
\hline \multicolumn{3}{|l|}{ Continent of origin $n$} \\
\hline $\begin{array}{l}\text { Asia (Afganistan, China, India, Pakistian, Phillipines, Russia, and South } \\
\text { Korea) }\end{array}$ & 22 & \\
\hline Europe (Hungary, Poland, Turkey and Ukraine) & 10 & \\
\hline Africa (Egypt, Tunisia, Eretria) & 4 & \\
\hline South America & 1 & \\
\hline \multicolumn{3}{|l|}{ Current Health Status } \\
\hline \multicolumn{3}{|l|}{ How is your health at present? } \\
\hline Good & $18(64.3 \%)$ & $6(66.7 \%)$ \\
\hline Alright & $10(35.7 \%)$ & $3(33.3 \%)$ \\
\hline Bad & $\mathrm{N} / \mathrm{A}$ & N/A \\
\hline \multicolumn{3}{|l|}{ Do you get tired easily } \\
\hline Yes & $6(21.4 \%)$ & $2(22.2 \%)$ \\
\hline No & $4(14.3 \%)$ & $3(33.3 \%)$ \\
\hline Sometimes & $18(64.3 \%)$ & $4(44.4 \%)$ \\
\hline
\end{tabular}




\begin{tabular}{|lll|}
\hline & Female & Male \\
\hline Yes & $18(64.3 \%)$ & $4(44.4 \%)$ \\
\hline Sometimes & $7(25 \%)$ & $3(33.3 \%)$ \\
\hline No & $3(10.7 \%)$ & $2(22.2 \%)$ \\
\hline Missing & N/A & $1(11.1 \%)$ \\
\hline
\end{tabular}

\section{Data collection.}

The focus group discussion (FGD) questions were developed in consultation with the settlement agency staff and focused on a) the clients' perceptions of health and the services needed to stay healthy; $b$ ) differences between the healthcare systems in the clients' countries of origin and Canada; c) access to healthcare services; $d$ ) challenges clients faced when accessing care in Canada; and e) how clients made decisions about healthcare. Clients received the questions before the FGD to organize their thoughts. Medical students representing specific ethnic groups and speaking additional languages assisted with data collection and interpretation during the FGDs.

Three FGDs were held at the settlement agencies and lasted 2 hours with breaks for refreshments. Each FGD was attended by $10-15$ clients and subgroups of 3-4 clients were coordinated by a facilitator speaking the same language. Clients with language barrier were supported by facilitators speaking their language, other clients with advanced English language proficiency, or language interpreters.

Responses from clients were written down by facilitators and reread to the clients for accuracy. Some clients had written down their thoughts in English using online translators prior to the actual FGD to help them verbalise their thoughts with ease. Clients read out their responses during the FGDs and handed those in after the FGDs. Facilitators also wrote field notes of the salient points emerging from these sessions and their reflections, which informed subsequent FGDs. None of the clients received any services from any of the family physicians on the research team during data collection. Complementary child minding, light refreshments, and a \$20 gift card to a grocery store were provided as incentives to participate.

\section{Part 2}

\section{Participants.}

In part 2, healthcare providers' perspectives on caring for immigrants and refugees were explored to show a more comprehensive view of the situation. Seventeen healthcare providers signed the consent form: four family physicians, two family physicians providing obstetrical care, a psychiatrist, a registered nurse, a lab technician, a pharmacist, a nutritionist, a psychiatric social worker, a counsellor, an exercise therapist, an ultrasound technician, an executive director, and a receptionist. They were recruited from a 
community clinic that predominantly served refugees, immigrants, and other socio-economically disadvantaged populations in the city, other medical clinics in the city, and a hospital.

\section{Data Collection.}

Healthcare providers serving immigrants and refugees participated in an hour-long, in-depth individual interview focusing on a) health services required to better address the healthcare needs of immigrants and refugees; b) the availability of culturally responsive healthcare services; and c) the barriers to providing such care. Family physicians on the research team with extensive experience caring for immigrants and refugees assisted with the development of the interview guide and data collection in this phase. Interviews were carried out in English, and was audio recorded. No compensation was provided.

\section{Analysis}

The FGDs and healthcare provider interviews were transcribed verbatim. The data was analyzed qualitatively using NVIVO version 9 and the procedure proposed by Miles, Huberman, and Saldana [35, 36]. During the preliminary data analysis, two rich transcripts were open coded by a team of researchers. Although the project was carried out to explore barriers to healthcare access for immigrants, language barriers emerged as a distinct theme impacting various aspects of care during data analysis. The results were shared with the settlement agency representatives. A collective decision was made to highlight the impacts of limited English language proficiency on healthcare access, utilization, and outcomes for immigrants in this manuscript. This framework guided the rest of the data analysis.

Data was broken into 120 base-level codes. The base-level codes were reviewed a second time, a nd codes with similar concepts were consolidated into 45 intermediate codes.

The intermediate codes were categorized under 11 sub-themes. Titles were assigned to each sub-theme to highlight the diverse and pertinent concepts represented by each sub-theme. The sub-themes were then organized under three central themes. Diagrammatic representations showed the relationship between the 11 sub-themes and the three themes and is illustrated in Fig. 1. Field notes maintained by facilitators were used to cross reference the themes emerging during data analysis to ensure all pertinent themes were included.

The diagram demonstrating the relationship with the subthemes were approved by all team members.

\section{Results}

Impacts of limited English language proficiency has been summarized under three main themes as follows.

\section{Theme 1: Ability to engage with the healthcare system}


Language proficiency significantly impacted a client's ability to identify services needed, to secure appointments, and to effectively engage with healthcare providers while seeking care and managing post-appointment care and follow-up. Information about healthcare services is usually provided in English or French. Thus, a client with language barriers lacked adequate information about available services and was unable to access services promptly. Clients with language barriers are less likely to actively seek health and or mental health services when needed, as is evident from a client's comment: "No do not know about mental health services because of the language problem. Can I go to the hospital to access it?" [client]

The range of healthcare services offered in different countries differs significantly. Lack of knowledge about existing healthcare services in the city created a barrier, which was greatly influenced by clients' local language proficiency. A healthcare provider in the study commented that,

We need to make the community or the clients' population know that this is available for you and this is the process how you get access to this service, the language barrier is a huge barrier for this population and to access like any health care service.

The way in which healthcare is organized and coordinated varies from country to country., and for newcomers, understanding the services provided within the host country largely depends on their ability to decipher information about them. Those with language limitations might not know how to access various healthcare services. This can lead to a misunderstanding between the client and the provider, causing frustrations and unfulfilled expectations for both, as one healthcare provider noted:

I offer free prescription delivery, but clients didn't come to the door, they didn't understand that the delivery person is delivering it and all they're doing is going to the door, ringing the doorbell expecting them to be let in. On numerous occasions, we were unsuccessful because they [clients] wouldn't open the door, um there was no one there or-they did not understand, so, and unless someone on the other end speaks English and tells us they're going to be there, we won't deliver now.

Experience with healthcare delivery in clients' countries of origin and cultural beliefs about health and what healthcare services should be accessed can interfere with their healthcare access. Language barriers may impede clients' abilities to understand the difference between healthcare organizations in Canada and in their countries of origin, leading to the underutilization of healthcare services, as one healthcare provider explained:

If you don't know their language, it becomes difficult to provide care to them. Also, cultural beliefs can interfere with access to care. For example, they [immigrants and refugees language barrier] do not know how to access an optometrist or dentist. So, I have to give them a lot of information as they have no idea.

Due to language barriers, clients experienced difficulty following conversations with receptionists, providing proper documentation required for coordinating care, and booking and attending appointments. 
Clients with language barriers were less likely to seek clarifications when they did not understand instructions or to advocate for their needs. As one client noted, "I don't speak good English. Therefore, sometimes it is difficult to understand what the receptionist is saying."

Healthcare providers who are culturally attuned to the challenges that clients with language barriers face are often empathetic and accommodative and ensure that clients receive the required care. One healthcare provider noted,

They experience a barrier accessing health care due to language limitations. Some clients may have challenges with conceptualizing what constitutes good health. This is partly informed by the fact that most of them may have experienced marginalization for so long. Therefore, [clients] might not have the right access to information or ask the right question. I try to talk to them at their level of understanding.

The degree to which a client with limited language proficiency is able to access the healthcare services they need largely depends on their ability to understand information that is written in English and to understand how the healthcare system is organized.

\section{Theme 2: Ability to develop a therapeutic alliance with healthcare providers}

English language proficiency significantly affected the therapeutic relationship between patients and healthcare providers. Clients with language barriers were unable to explain their health conditions adequately, as one client noted:

Without proficiency in English, it is difficult talking to the health care provider. It's a problem to describe what you're feeling. It will be easier as a newcomer if they have a family doctor who speaks the same language. Like for children with pain, it is difficult for them to say what they want or to make them understand.

Clients reported difficulty asking questions about their health and understanding treatment instructions from healthcare providers. One client mentioned that,

Sometimes, the doctors describe the illness in a way that I don't understand what the doctors say. This makes it sometimes very hard to go to the doctors because of the language problems.

Healthcare providers were often concerned about getting adequate information about health concerns from patients with language barriers. They experienced difficulties during physical examinations or when providing treatment instructions, which can have adverse outcomes, as one healthcare provider explained:

Say I am treating an ear infection. I have told the clients many times that the medication is to be administered by mouth, but they thought it was to be installed in the ears. So, I have a couple of disastrous cases where I have prescribed medication where they don't realize it is given by mouth. I think 
also, when they don't understand, they feel uncomfortable to ask for clarification. They get very embarrassed and they get very frustrated.

Families often bring interpreters to the clinic appointment or use volunteers working within the healthcare system. Often, these interpreters lack adequate skills and training to carry out medical translation, which creates additional challenges. Healthcare providers may not feel confident that instructions are being translated verbatim. They also noted that often they received a summarized or concise version of what the clients narrated and wondered whether valuable contextual information was lost during translation. This can be frustrating for the healthcare providers and interfere with the development of the therapeutic alliance, as a healthcare provider pointed out:

Some of the barriers I've experienced, those mainly had to do with communication and interpreters. I guess sometimes I wonder with the translation, what is being said to the patient. because they have quite a long discussion, and then when I ask the interpreter what was said... oh, they have no questions. *laughs* so I'm not sure what the conversation was, so that can be a little bit, um, frustrating.

Further, some interpreters might provide a cultural and religious interpretation of strategies that might not align with western medical care, as this healthcare provider explained:

There are sometimes when the clients will bring in their interpreters that I don't feel that my teaching and my advice is being given to them appropriately or word for word. I find that the personal interpreters they bring in will contraindicate and conflict with what I am telling the client because they will say "no that's not how we do things" instead of telling the client what I as a practitioner would like them to do.

Sometimes, interpreters are less helpful in assisting client-provider communication and may become an impediment to the therapeutic alliance, as a healthcare provider noted:

Sometimes working with an interpreter is difficult because you don't always know whether the translator translates exactly what you're trying to come across or explain.

Medical interpreters' presence can create privacy and confidentiality issues, especially for clients with mental health issues. Interpreters assisting clients with mental illness require training to create culturally safe interactions, lest the interaction become more injurious to the client than the illness itself. The excerpt below from a healthcare provider is an excellent example of culturally unsafe medical translation.

I had this case where the interpreter was not trained in mental health, and they found the conversation to be funny, so it was an elderly Asian lady who had delusions and hallucinations-well, we had a hard time with that. The interpreter was laughing.

Some clients were uncomfortable receiving language assistance from family or individuals of the same community. Moreover, healthcare providers were sometimes concerned about the quality of translation services provided to their clients. Healthcare providers observed that some interpreters struggled to explain instructions adequately during sample collection and diagnostics tests, leading to delays in the 
treatment process and linkage to treatment. One healthcare provider conveyed the issues with inadequate medical translation:

I requested that the client present with a stool sample in the container provided. A couple of times, some clients showed up with urine in there rather than stool. This is after numerous explanations with an interpreter present.

Another healthcare provider mentioned that

Giving simple instructions such as the need for a full bladder before ultrasound, many don't understand what bladder is. Last week I tried to conduct spirometry on a patient even with the presence of an interpreter and I was not successful. He just didn't understand. I guess he [interpreter] did not translate accurately.

Effective communication between healthcare providers and clients is vital for providing safe healthcare.

\section{Theme 3: The ability of the healthcare system to meet the clients' needs}

Due to language barriers, clients have difficulty understanding and following treatment plans. Healthcare providers often found it challenging to share the medical information required to manage illnesses. The language barrier created dissatisfaction among both the clients and the healthcare providers, as one client noted:

What is the point of seeing a doctor if I do not feel satisfied? First, you must make appointments, manage everything at home to go for that appointment, and then still wait when you reach there, and then the doctors hardly spend time with you. I had problems with the iron levels, and the doctors told me to get a blood test, after which he prescribed iron pills. I asked the doctors how many to take, but he did not explain it properly. He first said that I should take one pill a day, then when I ask if that will be enough, they said I take 2 to 3 pills. How can he advise me like that without explaining it properly?

Healthcare providers were concerned that clients with language barriers might not understand medical instructions provided during consultation, leading to fatal consequences, as one healthcare provider explained:

First of all, they [clients] might not understand what I'm telling them when I'm asking them to administer insulin themselves and increasing their doses based on their numbers. A lot of times they're very confused on that fact and the translation, something's getting lost in the translation. Any misunderstanding can put them in a very dangerous situation if they give themselves too much insulin.

Language ability can interfere with chronic disease management, which requires continual monitoring through regular clinic appointments. Even with medical translation, some clients may not comprehend the steps in the treatment plan required to manage chronic conditions, such as hypertension, effectively. 
Patients with language barriers might require additional support with setting up follow-up appointments, refilling prescriptions, and adhering to medical instructions. In the absence of such support, treatment adherence might be poor. A healthcare provider describes what happens when the clients don't receive post-appointment follow-up or support:

A lot of them [clients] have chronic conditions such as hypertension and don't come for a routine checkup. You'll see them and start them on medication and try to emphasize that this is long term treatment, and they will need to come back in a month for a check-up. You'll see that they've shown up a year later, and yet they were prescribed medications to last them for one month only and didn't renew them even though they had renewals. They will show up a year later with a headache or something, and their blood pressure is way out of control. I see that a lot.

Effective coordination of care requires good communication between patients and healthcare providers. During consultation sessions, patients must understand healthcare providers' instructions regarding follow-up, treatment options, or additional required tests.

\section{Discussion}

This study includes the perspectives of immigrants in a Canadian city and healthcare providers serving them. Consistent with the literature, both patients and providers univocally agreed that limited English language proficiency significantly impacts access to care, quality of care received, and health outcomes for immigrants throughout the continuum of care [3, 15-17, 24-28, 30, 32, 34]. This study's results highlighted four ways that limited English language proficiency can interfere with immigrants' healthcare access and health outcomes.

As observed by Floyd and Sakellariou (2017), clients in our study were unaware of the available healthcare services, lacked knowledge about ways to navigate the healthcare system, and were unable to advocate for needed services [24]. Language barriers impacted clients' engagement with prevention, health promotion, and allied health services, which can create the misperception that they are disengaged in care. Other studies have also identified language barriers as a factor influencing access to and use of preventative medicine and screens $[29,37-39]$.

Clients and providers consistently mentioned that language barriers interfered with the development of therapeutic relationships. As observed in other studies, language barriers impeded effective health information sharing and communication between patients and providers, thereby undermining trust [16, 25-29]. Language barriers interferes with the ability to find information about healthcare services and eligibility leading to fragmented, suboptimal care and/or delayed linkage with appropriate care $[4,11,29]$. Similar to what De Moissac and Bowen (2019) observed, the clients in this study also mentioned difficulty describing pain and other symptoms to their healthcare providers, which can interfere with accurate diagnoses $[24,31,40]$. Clients with limited language abilities are at risk of delaying seeking treatment [4, 41], misdiagnosis, or mismanagement of their conditions [41, 42]. Like those reported in other studies, our results also demonstrated specific instances where language barriers increased the 
chances of medical errors and harms due to patients' inabilities to understand and/or follow treatment plans $[15,17,18,24,41]$.

Consistent with the findings of systematic reviews $[16,43]$, the providers in this study indicated that interpreters were helpful. As was also observed in other studies [16, 28-29], clients in this study also emphasized the need for bilingual healthcare providers. Community health navigators can help improve access to primary and preventative healthcare services while acting as the cultural brokers and language interpreters [44].

Molina and Kasper (2019) called for language-concordant care, as it has been shown to provide safe and high-quality care.

Language-concordant care also reduces vulnerability and removes barriers to care for those speaking different languages [28].

The study results add to the discussion in the literature about the challenges that arise when untrained interpreters are involved [46]. Consistent with the literature, the healthcare providers in this study indicated that interpreters' roles are often not structured. Instead of translating line-by-line, an interpreter might summarize information or provide their own interpretation of what the patient and/or the provider said, leading to suboptimal conversation and care $[3,37]$. Interpreters are also unsure about their role in medical translation [18]. Although healthcare providers wanted verbatim translation in our study, other studies observed that healthcare providers might expect interpreters to also act as cultural brokers or care coordinators $[3,18,37]$. Our results provided evidence of situations when some medical interpreters could not provide culturally safe translation support, especially when sensitive and taboo topics were involved [3]. Language barriers complicate healthcare delivery, requiring extra time and increases stress and workload $[26,37,43,47]$ and providers might not feel comfortable or prepared to provide care [24].

In this study, clients and providers both indicated that multiple sessions might be required to communicate instructions for treatment and sample collection [37]. Like the study carried out by Ali and Watson (2018) in the United Kingdom, the healthcare providers in this study also reported that language interpreters might not be able to translate treatment plans, instructions for sample collection, or instructions for screenings because of their lack of medical knowledge. As discussed in the literature the healthcare providers in this study also highlighted issues with privacy and confidentiality when untrained interpreters, family members, or individuals from the same ethnic groups are involved $[3,38,46,48]$.

Studies indicate that clients with limited English language proficiency prefer professional genderconcordant interpreters over family members [49]. Although studies show that without medical interpreters the quality of care is compromised for clients with limited language proficiency, interpretation errors often occur when untrained or ad hoc interpreters are used [16, 24, 25, 34, 46, 48, 50]. Professional interpreters raise the quality of clinical care compared to non-trained interpreters $[46,50]$.

Finally, the present study results highlighted how English language proficiency creates an additional layer of barrier to healthcare access, utilization, and patient satisfaction [3]. Inability to communicate 
effectively with healthcare providers creates dissatisfaction for patients because their needs were not communicated to and understood by the healthcare providers and they are not getting the services need $[16,25]$. Moreover, the language barrier between the healthcare provider and client limits the healthcare provider's ability to provide care in a timely, safe manner; subsequently, the client's needs are unmet $[4,16$, $17,26,31]$.

Language barriers also create dissatisfaction for healthcare providers as they are not able to effectively engage patients with health promotion and prevention programs [37, 39], offer additional supports like home delivery for medications, or support them with treatment adherence. Language barrier might cause embarrassment, disempower patients, and undermine patients' confidence [24, 27, 29]. Floyd \& Sakellariou (2017) observed that refugee women with language barriers are likely to experience racism, and healthcare providers might be reluctant to engage them in healthcare decision making.

Our results indicate that the mere presence of adequate healthcare services is not enough. It is essential to ensure equitable access for all. Floyd and Sakellariou (2017) observed that the Canadian healthcare system is organized on the assumption that service seekers can read and understand English, which marginalizes immigrants, refugees, and others with lower literacy and limited English language proficiency.

Parsons, Baker, Smith-Gorvie, and Hudak (2014) raise several important issues that arise when working with the patients with limited English language proficiency. It is unclear who is responsible for ensuring that communication between providers and patient is adequate [51]. In the current context of how healthcare is delivered, there is lack of strategies to determine if the information received from patients with language barriers is adequate for providing care. Guidelines are required for healthcare providers outlining when language interpreters should be involved. Papic et al. (2012) highlighted the need for clear directives for determining who is responsible for arranging interpreters and finding ways to enhance the involvement of professional interpreters and multicultural clinics where available.

As a country that promotes and celebrates multiculturalism, the Canadian Charter of Rights and Freedoms (1982) guarantees equality rights, such that Canadians are to be treated with the same respect, dignity, and consideration regardless of race, nationality, ethnicity, color, religion, sex, or age [52]. Therefore, access to healthcare services should not be contingent on language proficiency. Healthcare access needs to be regarded as a basic human right under the Charter. Although most immigrants arrive with better health statuses than the local population, largely attributed to initial health selectivity and the Canadian immigration policy, their health statuses tend to decline over time to levels worse than nativeborn citizens $[3,9,53-55]$. This deterioration has been partly attributed to discrimination and unfair treatment that immigrants experience in the healthcare system [9].

Aery (2017) [56] proposed that a health equity perspective is required when developing healthcare systems that accommodate and address the socio-cultural barriers that vulnerable populations, including immigrants and refugees, face. Ali and Waston (2018) proposed that addressing language barriers is an essential step towards providing culturally responsive and client-centered care. Patients, providers, and 
interpreters need to be engaged to understand the multi-layer barriers at the individual, community, and health-system levels and to address those needs [37].

\section{Limitation of the study}

A small number of clients from each ethnic group was recruited; therefore, results might not reflect the experience of the respective ethnic groups as a whole. With a larger number of female clients recruited in the study, the views are more reflective of female than male patients with limited language proficiencies. A small number of healthcare providers were recruited from each discipline. Further research is required to capture discipline-specific challenges that providers might encounter when caring for patients with limited language proficiencies.

\section{Implications for practice}

The results of the study are relevant for any country accepting immigrants from linguistically diverse countries. The results have implications for the delivery and coordination of medical care for immigrants and refugees with language barriers and for the education and training of healthcare providers caring for individuals with language barriers. The study results raise valid questions about involving interpreters during medical consultation. The development of guidelines for healthcare providers caring for immigrants and refugees and others with language barriers and/or low literacy might help address the challenges identified in this study. Through professional courses and continued education, healthcare providers should be equipped with adequate knowledge and skills to care for patients with the language barrier [45].

\section{Conclusions}

An examination of medical translation policies and practices is urgently needed to identify culturally safe strategies. These include providing cultural training to interpreters, hiring professional interpreters, and supporting clients after medical consultations. Best practice guidelines are required to determine appropriate situations for engaging interpreters and to assist with interpreter recruitment. Provisions should be made for appropriate cultural and medical training for interpreters to adequately support patients with language barriers during different scenarios, such as for sample collection, before scans, or with prescriptions.

Interpreters should have clear instructions about whether only verbatim translation is required or they need to serve as cultural brokers and/or support clients with coordinating care and navigating the healthcare system. Medical interpreters should be integrated within the healthcare system [33]. A national strategy should be developed to train, support, and supervise interpreters adequately to ensure that they deliver safe, and impactful services [33].

\section{Abbreviations}


FGD = Focus Group Discussion

\section{Declarations}

\section{Ethics approval and consent to participate}

This study was approved by the Ethics Committee of the National Institute of Health Researchers (REB \#18-5307). All protocols were carried out in accordance with relevant guidelines and regulations. All participants provided informed consent before participating in the research activity.

\section{Consent for publication}

Not applicable.

\section{Availability of data and materials}

All data generated or analysed during this study are available from the corresponding author on reasonable request.

\section{Competing Interest}

The authors declare that they have no conflict of interest.

\section{Funding}

This project did not receive any financial support.

\section{Authors contributions}

Mamata Pandey: She developed the research plan, carried out stake holder consultation, prepared ethics application, collected data, analyzed data, prepared the first draft of the manuscript

Geoffrey Maina: Assisted with finalizing methodology, data analysis, writing methodology, data analysis, results and implication section of the manuscript, extensively review and revised the manuscript.

Jonathan Amoyaw: Assisted with literature review, prepared the discussion, limitation and conclusion, reviewed and edited the manuscript.

Yiyan Li: Assisted with introduction, literature review, figures and tables and final editing of manuscripts 
Rejina Kamrul: Helped with ethics application, carried out consultation with community partners, development of focus group and health care provider interview guides, data collection and analysis and reviewed the final draft of the manuscripts

Clara Rocha Michaels: Assisted with consultation with stakeholders, reviewed ethics application, development of healthcare provider interview guides, data collection, data analysis and reviewed the final draft of the manuscripts

Razawa Maroof: Assisted with ethics application for part 2 of the study, assisted in the development of the interview questions for healthcare providers, carried out interviews with healthcare providers, reviewed the data analysis and final draft of the manuscript.

\section{Acknowledgements}

We greatly appreciate the support received from the Executive Director of Regina Immigrant Women Center Mrs. Neelu Sachdev and her staff members during the project. We would especially like to thank the teachers facilitating the English language classes, for helping with participant recruitment, data collection, translation and data interpretation. We acknowledge the contributions of Cheghaf Madrati, Sarah Green Wood, Tooba Zahid, Fatima Ahmed and Tannys Bozdech undergraduate medical students who provided language support and assisted with writing the response during the focus group discussion. We also want to thank psychiatry resident Samra Sahlu for assistance with the healthcare provider interviews. Saskatchewan Health Authority and Department of Academic Family Medicine (Regina Campus) University of Saskatchewan provided in-kind support for the project.

\section{References}

1. International Organization for Migration (IOM): Key migration term [Internet]. https://www.iom.int/key-migration-terms. Assessed 26 Feb 2021.

2. Statistic Canada. Immigration and ethnocultural diversity: Key results from the 2016 Census [Internet]. 2017. https://www150.statcan.gc.ca/n1/en/daily-quotidien/171025/dq171025b-eng.pdf? st=WbM3u6Dy. Assessed 26 Feb 2021.

3. Ahmed S, Shommu NS, Rumana N, Barron GR, Wicklum S, Turin TC. Barriers to access of primary healthcare by immigrant populations in Canada: a literature review. J Immigr Minor Health. 2016;18(6):1522-40. doi:10.1007/s10903-015-0276-z.

4. Marshall EG, Wong ST, Haggerty JL, Levesque JF. Perceptions of unmet healthcare needs: what do Punjabi and Chinese-speaking immigrants think? A qualitative study. BMC Health Serv Res. 2010;10(1):1-8.

5. Delara M. Social determinants of immigrant women's mental health. Adv Public Health. 2016 Mar 7;2016. doi:10.1155/2016/9730162. 
6. Kirmayer LJ, Narasiah L, Munoz M, Rashid M, Ryder AG, Guzder J, et al. Common mental health problems in immigrants and refugees: General approach in primary care. 2011;183(12): E959-E967. doi:10.1503/cmaj.090292.

7. Fuller-Thomson E, Andrea M, Noack AM, George U. Health Decline Among Recent Immigrants to Canada: Findings From a Nationally-representative Longitudinal Survey. Can J Public Health. 2011;102(4):273-80.

8. Gushulak BD, Pottie K, Roberts JH, Torres S, DesMeules M. Migration and health in Canada: Health in the global village. 2011;183(12):E952-E958. doi:10.1503/cmaj.090287.

9. De Maio FG, Kemp E. The deterioration of health status among immigrants to Canada. Glob Public Health. 2010 Sep 1;5(5):462-78. doi:10.1080/17441690902942480.

10. Aery A. Innovations to champion access to primary care for immigrants and refugees. Wellesley Institute. 2017 Mar. https://www.wellesleyinstitute.com/wp-content/uploads/2017/03/Innovationsto-champion-access-to-primary-care-for-immigrant-and-refugees.pdf.

11. Chiarenza A, Dauvrin M, Chiesa V, Baatout S, Verrept H. Supporting access to healthcare for refugees and migrants in European countries under particular migratory pressure. BMC Health Serv Res. 2019 Dec;19(1):1-4.

12. Clarke J. Difficulty accessing health care services in Canada [Internet]. Ottawa: Statistics Canada. 2016. https://www150.statcan.gc.ca/n1/en/pub/82-624-x/2016001/article/14683-eng.pdf? st=49Q0baTj. Assessed 21 Feb 2021.

13. Kalich A, Heinemann L, Ghahari S. A scoping review of immigrant experience of health care access barriers in Canada. J Immigr Minor Health. 2016 Jun 1;18(3):697-709. doi:10.1007/s10903-0150237-6.

14. Luiking ML, Heckemann B, Ali P, Dekker-van Doorn C, Ghosh S, Kydd A, Watson R, Patel H. Migrants' healthcare experience: a meta-ethnography review of the literature. J Nurs Scholarsh. 2019 Jan;51(1):58-67. doi:10.1111/jnu.12442.

15. Bowen S. The impact of language barriers on patient safety and quality of care. Société Santé en Français. 2015 Aug.

16. Joshi C, Russell G, Cheng IH, Kay M, Pottie K, Alston M, Smith M, Chan B, Vasi S, Lo W, Wahidi SS. A narrative synthesis of the impact of primary health care delivery models for refugees in resettlement countries on access, quality and coordination. Int J Equity Health. 2013 Dec;12(1):1-4. doi:10.1186/1475-9276-12-88.

17. Ali PA, Watson R. Language barriers and their impact on provision of care to patients with limited English proficiency: Nurses' perspectives. J Clin Nurs. 2018 Mar;27(5-6):e1152-60. doi:10.1111/jocn.14204.

18. Messias DK, McDowell L, Estrada RD. Language interpreting as social justice work: perspectives of formal and informal healthcare interpreters. Adv Nurs Sci. 2009 Apr 1;32(2):128-43. doi:10.1097/ANS.0b013e3181a3af97. 
19. Bauldry S, Szaflarski M. Immigrant-based disparities in mental health care utilization. Socius. 2017 Jan 4;3. doi:10.1177/2378023116685718.

20. Na S, Ryder AG, Kirmayer LJ. Toward a culturally responsive model of mental health literacy: Facilitating help-seeking among East Asian immigrants to North America. Am J Community Psychol. 2016 Sep;58(1-2):211-25.

21. Anand AS, Cochrane R. The mental health status of South Asian women in Britain: A review of the UK literature. Psychol Dev Soc J. 2005 Sep;17(2):195-214. doi:10.1177/097133360501700207.

22. Chen AW. Immigrant access to mental health services: Conceptual and research issues. Canadian Issues. 2010 Jul 1:51-54.

23. Fang L. Mental health service utilization by Chinese immigrants: Barriers and opportunities. Canadian Issues. $2010 \mathrm{Jul}$ 1:70-118.

24. Goenka PK. Lost in translation: impact of language barriers on children's healthcare. Curr Opin Pediatr. 2016 Oct 1;28(5):659-66.

25. Ahmed S, Lee S, Shommu N, Rumana N, Turin T. Experiences of communication barriers between physicians and immigrant patients: A systematic review and thematic synthesis. Patient Exp J. 2017;4(1):122-4.

26. Al Shamsi H, Almutairi AG, Al Mashrafi S, Al Kalbani T. Implications of language barriers for healthcare: a systematic review. Oman Med J. 2020 Mar;35(2):e122.

27. Dastjerdi M, Olson K, Ogilvie L. A study of Iranian immigrants' experiences of accessing Canadian health care services: a grounded theory. Int J Equity Health. 2012 Dec;11(1):1-5. doi:10.1186/14759276-11-55.

28. Floyd A, Sakellariou D. Healthcare access for refugee women with limited literacy: layers of disadvantage. Int J Equity Health. 2017 Dec;16(1):1-0.

29. George P, Terrion JL, Ahmed R. Reproductive health behaviour of Muslim immigrant women in Canada. Int J Migr Health Soc Care. 2014 Jun 10.

30. Higginbottom G, Safipour J. Access to primary health care by new and established immigrants in Canada. J Family Med Community Health. 2015;2(5):1-7.

31. van Rosse F, de Bruijne M, Suurmond J, Essink-Bot ML, Wagner C. Language barriers and patient safety risks in hospital care. A mixed methods study. Int J Nurs Stud. 2016 Feb 1;54:45-53.

32. Gulati S, Watt L, Shaw N, Sung L, Poureslami IM, Klaassen R, Dix D, Klassen AF. Communication and language challenges experienced by Chinese and South Asian immigrant parents of children with cancer in Canada: implications for health services delivery. Pediatr Blood Cancer. 2012 Apr;58(4):572-8.

33. Bowen S. Language barriers in access to health care. Ottawa: Health Canada; 2001 Nov.

34. Laher N, Sultana A, Aery A, Kumar N. Access to language interpretation services and its impact on clinical and Patients outcomes: A scoping review. Toronto: Wellesley Institute: Advancing Urban Health. 2018:1-78. 
35. Miles MB, Huberman AM, Saldaña J. Qualitative data analysis: A methods sourcebook. $4^{\text {th }}$ Sage publications; 2019 Jan.

36. QSR International Pty Ltd. Powerful research, simplified [Internet]. Doncaster: QSR International Pty Ltd. https://www.qsrinternational.com/nvivo-qualitative-data-analysis-software/about/nvivo. Assessed 26 Feb 2021.

37. Bruce KH, Schwei RJ, Park LS, Jacobs EA. Barriers and facilitators to preventive cancer screening in Limited English Proficient (LEP) patients: Physicians' perspectives. Commun Med. 2014;11(3):235247. doi:10.1558/cam.v11i3.24051.

38. Marques P, Nunes M, da Luz Antunes M, Heleno B, Dias S. Factors associated with cervical cancer screening participation among migrant women in Europe: a scoping review. Int J Equity Health. 2020 Dec;19(1):1-5.

39. Ferdous M, Lee S, Goopy S, Yang H, Rumana N, Abedin T, Turin TC. Barriers to cervical cancer screening faced by immigrant women in Canada: a systematic scoping review. BMC Womens Health. 2018 Dec;18(1):1-3. doi:10.1186\%2Fs12905-018-0654-5.

40. Bisch off A, Bovier PA, Isah R, Françoise G, Ariel E, Louis L. Language barriers between nurses and asylum seekers: their impact on symptom reporting and referral. Soc Sci Med. 2003 Aug 1;57(3):50312. doi:10.1016/s0277-9536(02)00376-3.

41. De Moissac D, Bowen S. Impact of language barriers on quality of care and patient safety for official language minority Francophones in Canada. J Patient Exp. 2019 Mar;6(1):24-32. doi:10.1177/2374373518769008.

42. Reitmanova S, Gustafson DL. "They can't understand it": maternity health and care needs of immigrant Muslim women in St. John's, Newfoundland. Matern Child Health J. 2008 Jan 1;12(1):101-11. doi:10.1007/s10995-007-0213-4.

43. Papic $O$, Malak Z, Rosenberg E. Survey of family physicians' perspectives on management of immigrant patients: attitudes, barriers, strategies, and training needs. Patient Educ Couns. 2012 Feb 1;86(2):205-209. doi:10.1016/j.pec.2011.05.015.

44. Shommu NS, Ahmed S, Rumana N, Barron GR, McBrien KA, Turin TC. What is the scope of improving immigrant and ethnic minority healthcare using community navigators: A systematic scoping review. Int J Equity Health. 2016 Dec;15(1):1-2. doi:10.1186/s12939-016-0298-8.

45. Molina RL, Kasper J. The power of language-concordant care: a call to action for medical schools. BMC Med Educ. 2019 Dec;19(1):1-5.

46. Flores $\mathrm{G}$. The impact of medical interpreter services on the quality of health care: a systematic review. Med Care Res Rev. 2005 Jun;62(3):255-99. doi:10.1177/1077558705275416.

47. Gerchow L, Burka LR, Miner S, Squires A. Language barriers between nurses and patients: A scoping review. Patient Educ Couns. 2020 Sep 18.

48. Squires A. Evidence-based approaches to breaking down language barriers. The Peer-Reviewed Journal of Clinical Excellence. 2017 Sep 1;47(9):34-40. 
49. Ngo-Metzger Q, Massagli MP, Clarridge BR, Manocchia M, Davis RB, lezzoni LI, Phillips RS. Linguistic and cultural barriers to care. J Gen Intern Med. 2003 Jan;18(1):44-52. doi:10.1046/j.15251497.2003.20205.x.

50. Karliner LS, Jacobs EA, Chen AH, Mutha S. Do professional interpreters improve clinical care for patients with limited English proficiency? A systematic review of the literature. Health Serv Res. 2007 Apr;42(2):727-54. doi:10.1111/j.1475.6773.2006.00629.x.

51. Parsons JA, Baker NA, Smith-Gorvie T, Hudak PL. To 'Get by'or 'get help'? A qualitative study of physicians' challenges and dilemmas when patients have limited English proficiency. BMJ Open. 2014 Jun 1;4(6). doi:10.1136/ bmjopen-2013-004613.

52. Department of Justice Canada. The rights and freedoms the Charter protects [Internet]. Ottawa: Department of Justice Canada. 2018. https://www.justice.gc.ca/eng/csj-sjc/rfc-dlc/ccrf-ccdl/rfcpcdlp.html. Assessed 26 Feb 2021.

53. Jass G, Massey DS. Immigrant health: selectivity and acculturation. IFS Working Papers; 2004.

54. Riosmena F, Kuhn R, Jochem WC. Explaining the immigrant health advantage: Self-selection and protection in health-related factors among five major national-origin immigrant groups in the United States. Demography. 2017 Feb 1;54(1):175-200. doi:10.1007/s13524-016-0542-2.

55. Vang ZM, Sigouin J, Flenon A, Gagnon A. Are immigrants healthier than native-born Canadians? A systematic review of the healthy immigrant effect in Canada. Ethn Health. 2017 May 4;22(3):209-41. doi:10.1080/13557858.2016.1246518.

56. Aery A. Innovations to champion access to primary care for immigrants and refugees. Wellesley Institute: Advancing Urban Health. 2017:1-14.

\section{Figures}


Lack of knowledge about healthcare services

Inability to navigate healthcare services

Difficulty coordinating healthcare services

Impact of culture on perception of health and

what healthcare services are needed

\section{Ability to engage with}

the healthcare system
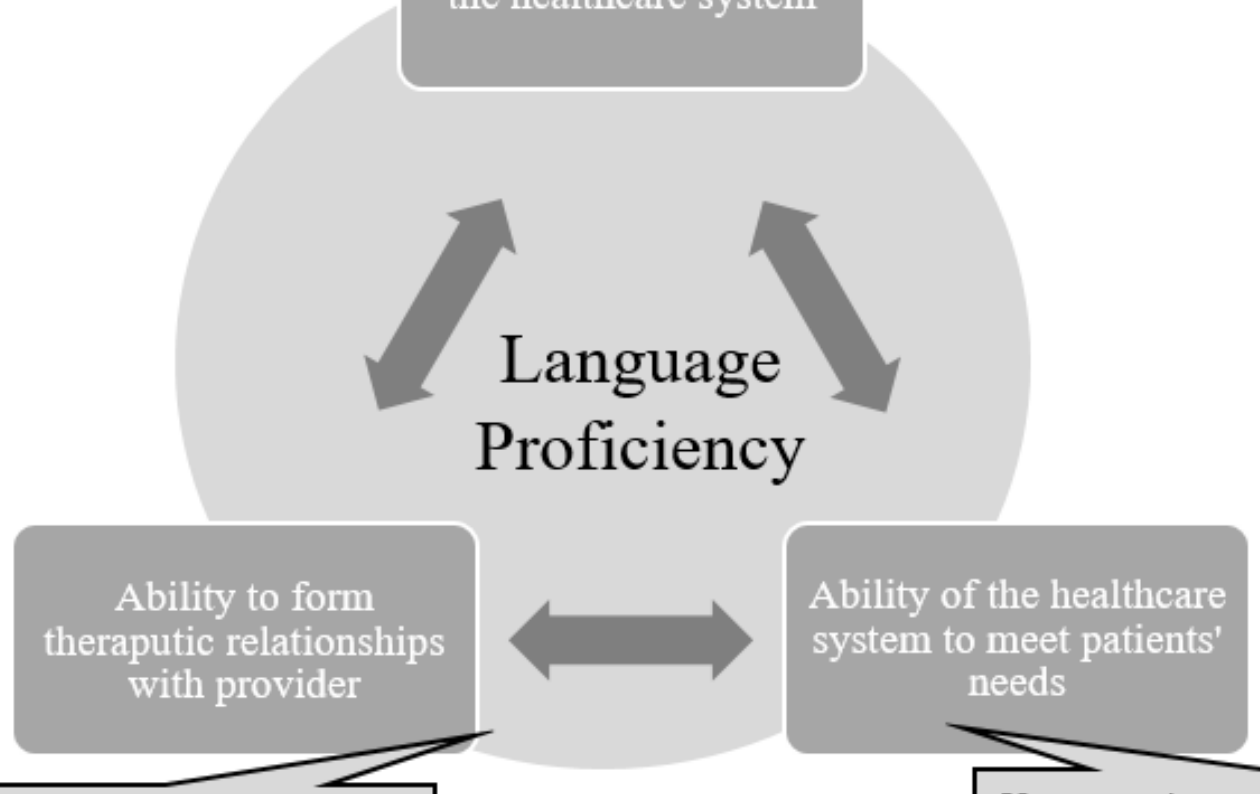

Patients ' inability to communicate with or understand providers

Providers unable to communicate

Challenges with untrained interpreters

Unmet needs

Difficulty understanding treatment plan

Poor disease management

Fewer preventative services used

\section{Figure 1}

Language Proficiency Leads to Poor Healthcare Access, Suboptimal Care, and Dissatisfaction with Care 